\title{
Difference in Lake Water Area Derived from Different Resolution Imagery
}

\author{
Rong $\mathrm{Xu}^{1}$, Zengxiang Zhang ${ }^{2}$, Feifei Sun ${ }^{2}$, Qingke Wen ${ }^{2}$, and Fang Liu ${ }^{2}$ \\ 1. School of Computer Science and Engineering, Chongqing Three Gorges \\ University, Chongqing 404000, China \\ 2. Institute of Remote Sensing and Digital Earth, Chinese Academy of Sciences, \\ Beijing 100094, China \\ E-mail: xurong010504@163.com
}

\begin{abstract}
In order to study the difference in lake water area derived from satellite images with different resolutions, the lake distribution maps with $30 \mathrm{~m}, 250 \mathrm{~m}$ and $500 \mathrm{~m}$ spatial resolution were derived from $H J-1 A / B$ and MODIS data acquired in the same period. It is showed that the area estimates derived from both $250 \mathrm{~m}$ MODIS and $500 \mathrm{~m}$ MODIS have strong correlations with those derived from $\mathrm{HJ}-1 \mathrm{~A} / \mathrm{B}$ data for lakes with area larger than $10 \mathrm{~km}^{2}$. And $500 \mathrm{~m}$ MODIS data can get nearly the same estimates as $250 \mathrm{~m}$ MODIS data. For further analysis of the difference in lake water area, those lakes were divided into three groups according to the shape indices of lake water body, which were calculated with the results extracted from $H J-1 A / B$ imagery. Taking $H J-1 A / B$ lake maps as reference, it is found that the error of estimates from MODIS data increases when the lake area decreases and the shape complexity increases.
\end{abstract}

Keywords: lake water area estimates; MODIS; HJ-1A/B; shape index

\section{Introduction}

Lake area is an important indicator for lake-related research. In the past several decades, dramatic changes have occurred in many lakes in the world, as shown in their size, morphology, and ecology [1-2]. With the climate change and human activities, especially the intensification of the unreasonable human activities, lake shrinking became one of the major environmental problems in some regions. Thus, it's very important to make real-time estimation of lake areas, which is meaningful for the sustainable development, utilization and protection of lakes [3].

Remote sensing technology has promoted human understanding of Earth surface and brought convenience for studying lake changes, especially changes in lake size, or lake water area, as it provides real-time and repeated land surface information [4-5]. According to the spatial resolution of the remote sensing data, most of the commonly used data for monitoring the lake water area can be divided into two categories. One is medium resolution data such as Landsat TM/ETM+, HJ-1A/B and ASTER imagery [6-11], and the other one is low resolution data such as NOAA AVHRR, MODIS and SPOT VEGETATION imagery [5,12-13]. This is just a broad categorization. With the rapid development of the remote sensing technology, the spatial resolution of satellite images becomes higher. Thus, it's difficult to give an accurate definition of high, medium or low resolution. Due to the scale effect of surface heterogeneity, spatial resolution of the imagery has an effect on the extraction by remote sensing. For example, the water area estimates derived from MODIS and Landsat ETM+ images acquired in the same period are different, and it is found that the error is small when edge density (the ratio of edge length to landscape area) of the region is low while the error is big when edge density of the region is high [14]. This research is made on regional water area estimates, and it can 
be inferred that there will be a similar conclusion for a single lake. In fact, it's necessary to study the difference in the lake water area estimates from images with different spatial resolution quantitatively, which is meaningful for selecting the appropriate data to monitor the lake water area. To investigate the effects of spatial resolution on lake surface monitoring, two Landsat ETM+ images were resampled to lower resolutions and used to extract water surface area of Poyang Lake [15]. It is showed that the accuracy decreases gradually at lower spatial resolution relative to $30 \mathrm{~m}$ resolution. However, the effects of spatial resolution on other lakes are rarely discussed.

In this paper, we studied the difference in the lake water area estimates extracted by three different spatial resolutions $(30 \mathrm{~m}, 250 \mathrm{~m}, 500 \mathrm{~m})$ data based on HJ-1A/B CCD and MODIS imagery, and analyzed the accuracy of water surface areas derived from MODIS data. In addition, the effect of water surface shape on water area estimation was discussed.

\section{Data and Study Area}

HJ-1A and HJ-1B are China's two small environment satellites. They were launched on September 6th, 2008, in Taiyuan Satellite Launch Center of Shanxi Province [16]. The CCD imagery of the two satellites has a spatial resolution of $30 \mathrm{~m}$, and it provides a high return frequency with two days interval, by constellation of the two satellites. In addition, the CCD cameras have four bands including blue, green, red and near-infrared spectrum, which is similar with the first four bands of the Landsat TM/ETM+ and MODIS satellite image. In some way, HJ-1 A/B CCD imagery has the advantages of both Landsat and MODIS images.

There are many lakes with different areas and shapes in Xinjiang and Tibet Province, which is suitable for the research in this paper. Therefore, this region was selected as sample areas for detailed analyzing. HJ-1A/B and MODIS data were acquired on the same day, in order to maintain the consistency of the actual lake area in the two images. The path and row number and acquisition time of HJ-1A/B data are as follows: 03271 acquired on 14 August 2010, 04760 acquired on 7 September 2010, 03676 acquired on 29 September 2010 and 03080 acquired on 29 October 2010. In the overlapping region, the imagery with better quality was selected to extract lake surface information.

HJ-1A/B data were downloaded from the China Resources Satellite Application Center, after radiometric correction and geometric correction. Ground control points were used for geometric precision correction of data, and data projection was transformed to the Albers Equal Area projection. MODIS surface reflectance data (MOD09), including the $250 \mathrm{~m}$ and $500 \mathrm{~m}$ resolution data, were downloaded from NASA website. After projection transformation using MRT software, MODIS data has the same projection as $\mathrm{HJ}-1 \mathrm{~A} / \mathrm{B}$ data. Since the coordinates of the MODIS and HJ-1A/B data have a certain offset, the image registration was performed and the registration error was less than one pixel. For subsequent processing, the MODIS and HJ-1A/B images were clipped to get the overlap area.

\section{Methods}

\subsection{Lake Water Body Mapping with HJ-1A/B Imagery}

The spectral response of water bodies in the HJ-1A/B imagery is similar to that of Landsat TM imagery. Therefore, the water extraction methods based on Landsat TM imagery can also be applied to HJ-1A/B imagery. For example, NDVI, NDWI and near-infrared band can be used for water body mapping [10-11]. NDWI is the normalized difference water index, and it is defined as:

$$
N D W I=\frac{\text { Green }-N I R}{\text { Green }+N I R}
$$


where Green and NIRare green band and near-infrared band reflectance, respectively. They correspond to band 2 and band 4 on HJ-1A/B images. NDWI can be effectively used to reduce the effects of vegetation, and highlight the information of water bodies [17]. It can be used to mapping water bodies by using the threshold segmentation approach.

After comparing the water body extracted by different methods visually, we decided to use an integrated water body mapping method with $\mathrm{HJ}-1 \mathrm{~A} / \mathrm{B}$ imagery, which combined the NDWI and near-infrared band. The method is presented in the following equations:

$N D W I>C \& N I R<D$

where $\mathrm{C}$ and $\mathrm{D}$ are thresholds for water body extraction.

Threshold segmentation is a key step in extracting water bodies from the background, and there are many methods that can bu used for image threshold segmentation. As the focus of this paper is not to find a better water extraction method, or a better thresholod sengmentaton method, the thresholds were determined by repeated experiments based on the histogram of NDWI and near-infrared band. It is a common and accurate method [11$18]$.

\subsection{Lake Water Body Mapping with MODIS Imagery}

$250 \mathrm{~m}$ resolution MOD09 dataset contains only the red band and near-infrared band. In the remote sensing images, water body has a lower reflectance than other features in the near-infrared band. In addition, the reflectance of water body in the near-infrared band is less than that in the red band, while the reflectance of vegetation and soil in the red band is less than that in the near-infrared band. These spectral characteristics can be used to distinguish water body from other features, and there are already several water extraction methods based on MODIS imagery. In this paper, an integrated water body extract method was used, and it is presented in the following equations[13]:

Red $-N I R>E \& N I R<F$

where Red and NIR are the red band and near-infrared band reflectance, respectively, and they correspond to band 1 and band 2 on MODIS image; E and F are the thresholds, which were determined by the same method in 3.1.

\subsection{Shape Index Calculation for Lake Surface}

Patch shape index is a landscape pattern index and can be used to measure the complexity of patch. In this study, two shape indices were used. The first index SI1 is defined as:

$S I 1=\frac{P}{A}$

where $\mathrm{P}$ and $\mathrm{A}$ are the perimeter and inner area of a patch, respectively. SI1 is the ratio of perimeter to inner area of a patch. It characterizes the boundary effect of a patch.

The second index SI2 is defined as:

$S I 2=\frac{P}{2 \sqrt{\pi A}}$ 
where $\mathrm{P}$ and $\mathrm{A}$ are the perimeter and inner area of a patch, respectively. Unlike SI1, SI2 is the ratio of patch perimeter to the perimeter of a circle with equal area with the patch. Taking the circle as a reference, SI2 can be used to represent the difference in shape between the patch and the circle. Typically, the value of SI2 increases with the increase of the complexity of the patch shape.

Satellite imagery with a higher spatial resolution is often used to validate the accuracy of the lake surface area retrieved from a lower spatial resolution imagery [5,12]. Since the spatial resolution of $\mathrm{HJ}-1 \mathrm{~A} / \mathrm{B}$ data is significantly higher than that of MODIS data, lake water body derived from $\mathrm{HJ}-1 \mathrm{~A} / \mathrm{B}$ is more reliable. Therefore, these two shape indices were calculated with the results from $\mathrm{HJ}-1 \mathrm{~A} / \mathrm{B}$ data.

\section{Results and Discussion}

\subsection{Lake Water area Derived from HJ-1A/B and MODIS}

Due to the relatively low spatial resolution, MODIS data is rarely used for monitoring lake surface changes in small scale. There are already some research shows that accuracy is relatively low when lake size is small. Therefore, 97 lakes with water area greater than $10 \mathrm{~km}^{2}$, based on the results derived from HJ-1A/B data, were selected to analyze the difference in lake water area estimated by images with different spatial resolution.

To compare the difference in lake area derived from HJ-1A/B and MODIS, the water area of all the lakes were used. For each lake, there are 3 area values from HJ-1A/B, 250 $\mathrm{m}$ and $500 \mathrm{~m}$ MODIS, respectively. Regression equations were established with these values in order to find the relationship between the lake area derived from $\mathrm{HJ}-1 \mathrm{~A} / \mathrm{B}$ data and MODIS data, as shown in table 1.

The lake water area estimates extracted by $250 \mathrm{~m}$ and $500 \mathrm{~m}$ MODIS data generally get a good regression results with those derived from $\mathrm{HJ}-1 \mathrm{~A} / \mathrm{B}$ data. The regression coefficients are 0.9821 and 0.9812 , respectively. $\mathrm{R}^{2}$ are 0.9999 and 0.9998 , respectively. The regression coefficient and $\mathrm{R}^{2}$ between $500 \mathrm{~m}$ and $250 \mathrm{~m}$ MODIS are 0.9996 and 0.9998 , respectively. The regression equation shows that both $250 \mathrm{~m}$ and $500 \mathrm{~m}$ MODIS data produce a certain degree of underestimation. Compared with the results from HJ$1 \mathrm{~A} / \mathrm{B}$ data, the relative errors of total lake water area from $250 \mathrm{~m}$ and $500 \mathrm{~m}$ MODIS data are $-2.59 \%$ and $-3.00 \%$, respectively.

\section{Table 1. Linear Regression Analysis between the Lake Water Areas Estimated by HJ-1A/B and MODIS Data}

\begin{tabular}{c|c|c}
\hline \hline Data Resolution & R Square & Regression Equations \\
\hline $30 \mathrm{~m}$ and $250 \mathrm{~m}$ & 0.9999 & $\mathrm{y}=0.9812 \mathrm{x}-1.2455$ \\
\hline $30 \mathrm{~m}$ and $500 \mathrm{~m}$ & 0.9998 & $\mathrm{y}=0.9818 \mathrm{x}-1.821$ \\
\hline $250 \mathrm{~m}$ and $500 \mathrm{~m}$ & 0.9998 & $\mathrm{y}=0.9996 \mathrm{x}-0.5648$ \\
\hline \hline
\end{tabular}

Figure 1 shows the lake water body maps in Nam Co region and Yangzhuoyongco region. In these two regions, the contrast between water bodies and the background land is clear, but the sinuosity of shorelines is different. In Nam Co region, the lake boundary is relatively smooth. It is shown that MODIS and HJ-1A/B images provide similar results, especially $250 \mathrm{~m}$ and $500 \mathrm{~m}$ MODIS images(figure $1 . \mathrm{a}, \mathrm{b}$ and c). Overall, the boundaries are continuous and reflect the basic characteristics of the lakes. In Yangzhuoyongco region, the lake boundary is rough and the sinuosity of shorelines is larger than that in Nam Co region. The big open water features are generally shown in both $\mathrm{HJ}-1 \mathrm{~A} / \mathrm{B}$ and MODIS images. Because of the significantly higher resolution $(30 \mathrm{~m})$, the $\mathrm{HJ}-1 \mathrm{~A} / \mathrm{B}$ image reveals more deteails and slight difference from the MODIS results for some lake segments. Some small water-bodies are not shown in MODIS images and the shoreline is 
not continuous in narrow water channels (figure 1.e and f). Compared with $\mathrm{HJ}-1 \mathrm{~A} / \mathrm{B}$ image, inaccurate and omitted extracting existed in MODIS images.

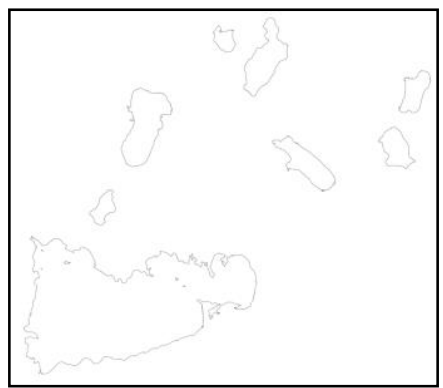

a

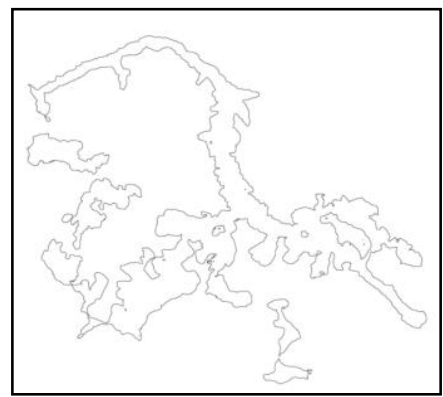

$\mathrm{d}$

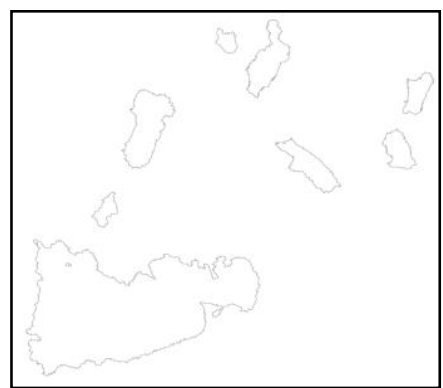

b

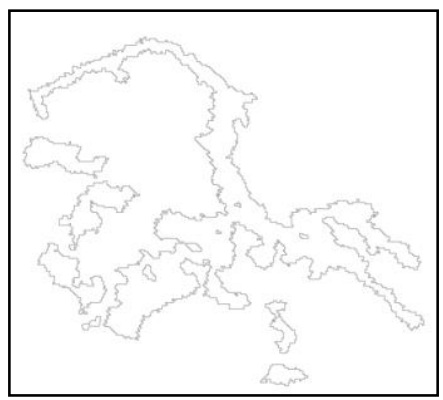

e

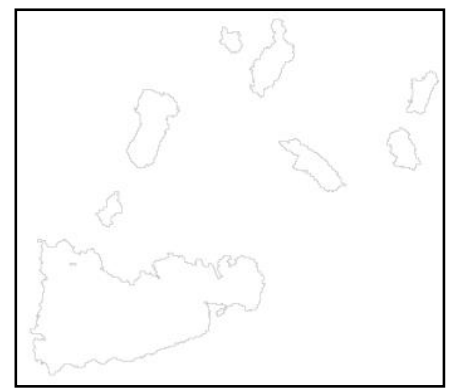

c

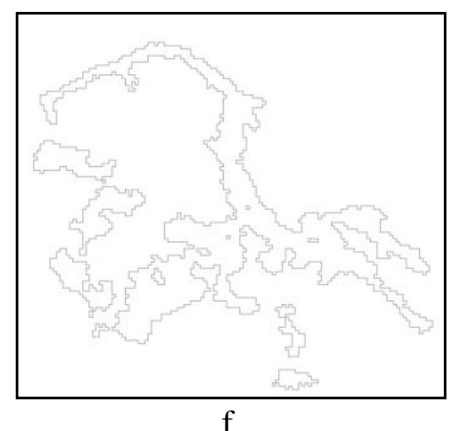

Figure 1. Lake Water body Maps in Nam Co Region (a, b and $c$ ) and Yangzhuoyongco Region (d, e and f). A and d were Derived from HJ-1A/B, b and e were Derived from $250 \mathrm{~m}$ MODIS, and $c$ and $f$ were Derived from 500 m MODIS

\subsection{Effects of Water Body Shape and Spatial Resolution on Lake Water Area Extraction}

In order to find the effect of water body shape on lake water area, two-dimensional scatter plots of the shape index and the relative error between the lake water area estimated by HJ-1A/B and MODIS were obtained (figure 2). It should be pointed out that the relative error in figure 2 is: the difference between the water area derived from the MODIS data and HJ-1A/B data divided by the area derived from $\mathrm{HJ}-1 \mathrm{~A} / \mathrm{B}$ data. As shown in figure 2, especially in 2(a) and 2(b), with the shape index increased the distribution of the relative error tends to be discrete and the average error shows an increasing trend. In addition, the relative errors of some lakes with different shape index are nearly equal, which shows that the error depends not only on the lake water shape.

For further analysis, these lakes were divided into three groups according to SI1, since the relative error showed a more obvious trend with SI1 changed. The first group, including 40 lakes with SI1 ranged from 0.2563 to 0.9870 , has an average lake area of $300.55 \mathrm{~km}^{2}$; the second group, including 40 lakes with SI1 ranged from 1.0315 to 1.9902 , has an average area of $59.94 \mathrm{~km}^{2}$; the third group, including 17 lakes with SI1 ranged from 2.0388 to 4.4064 , has an average area of $17.28 \mathrm{~km}^{2}$. These three groups represented the lakes with large area and simple shape, the lakes with moderate complex shape, and the lakes with small area and complex shape, respectively. 


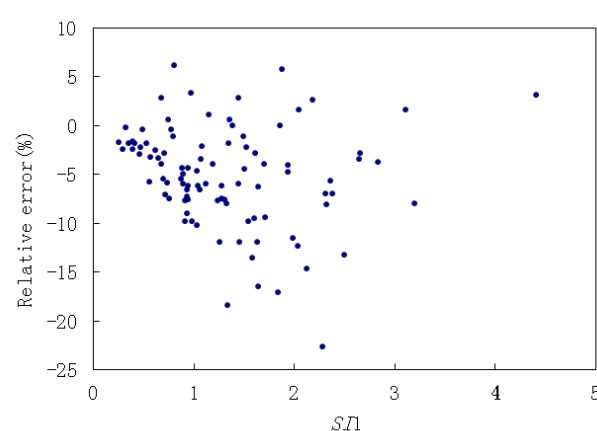

a

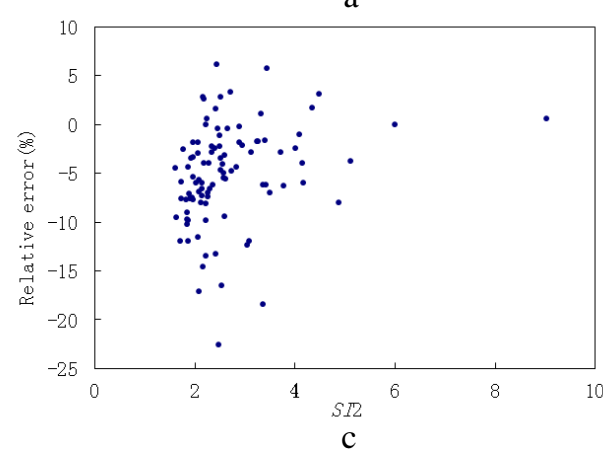

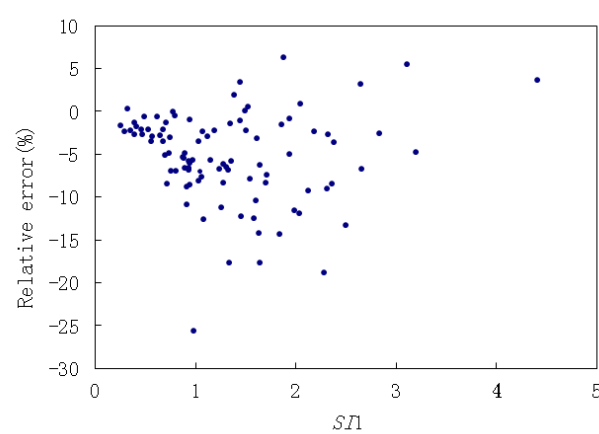

b

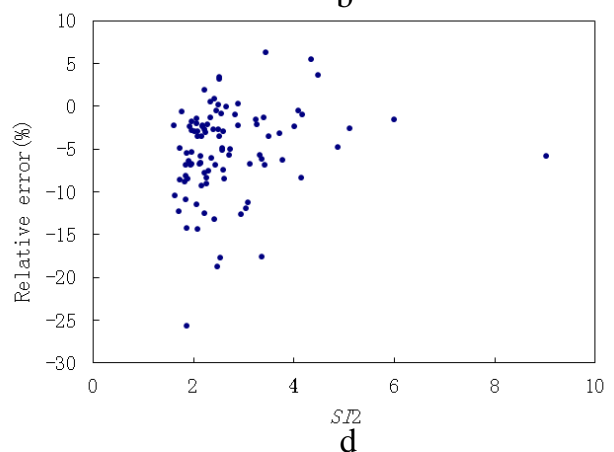

Figure 2. The Relationship between the Shape Index and the RError between the Lake Water area Estimated by HJ-1A/B and MODIS data. The Relative Error in a and $c$ is Calculated with the Lake Area Derived from 250 $m$ MODIS and $H J-1 A / B$, and in $b$ and $d$ is Calculated with the Lake Area Derived from $500 \mathrm{~m}$ MODIS and HJ-1A/B

For each group, the total lake water area derived from HJ-1A/B and MODIS data were calculated. Generally, compared with those derived from HJ-1A/B, MODIS underestimated the area of the three groups. $250 \mathrm{~m}$ MODIS underestimated by $2.20 \%$, $4.14 \%$ and $6.09 \%$; $500 \mathrm{~m}$ MODIS underestimated by $2.36 \%, 5.96 \%$ and $4.69 \%$. It indicates that the difference between the estimated lake water area from MODIS and HJ$1 \mathrm{~A} / \mathrm{B}$ shows an increasing trend as SI1 increased. This is because the effect of the spatial resolution on lake water area estimate is related to the complexity of lake water body shape. In low resolution images, the misclassified probability of pixels on the lake boundary is bigger for lakes with a more complex shape. However, the difference between the water area estimates derived from $250 \mathrm{~m}$ and $500 \mathrm{~m}$ MODIS are small, especially in the first group, which also illustrates that the shape of lake water would affect the lake water area estimates derived from different spatial resolution images.

Table 2. Lake Water areas Estimated by Three Different Resolution Images Data

\begin{tabular}{c|c|c|c|c|c}
\hline \hline Lake size & $\begin{array}{c}10-50 \\
\left(\mathrm{~km}^{2}\right)\end{array}$ & $\begin{array}{c}50-100 \\
\left(\mathrm{~km}^{2}\right)\end{array}$ & $\begin{array}{c}100-200 \\
\left(\mathrm{~km}^{2}\right)\end{array}$ & $\begin{array}{c}200-500 \\
\left(\mathrm{~km}^{2}\right)\end{array}$ & $\begin{array}{c}>500 \\
\left(\mathrm{~km}^{2}\right)\end{array}$ \\
\hline $\begin{array}{c}\text { Total area extracted by HJ- } \\
\text { 1A/B }\left(\mathrm{km}^{2}\right)\end{array}$ & 1195.19 & 1513.08 & 2027.48 & 2719.35 & 7636.18 \\
\hline $\begin{array}{c}\text { Total area extracted by } 250 \mathrm{~m} \\
\text { MODIS }\left(\mathrm{km}^{2}\right)\end{array}$ & 1120.45 & 1419.44 & 1979.06 & 2665.81 & 7515.00 \\
\hline $\begin{array}{c}\text { Total area extracted by } 500 \mathrm{~m} \\
\text { MODIS }\left(\mathrm{km}^{2}\right)\end{array}$ & 1126.25 & 1397.50 & 1963.06 & 2665.75 & 7486.75 \\
\hline
\end{tabular}




\begin{tabular}{c|c|c|c|c|c}
$\begin{array}{c}\text { Relative error between } 250 \mathrm{~m} \\
\text { MODIS and HJ-1A/B }(\%)\end{array}$ & -6.25 & -6.19 & -2.39 & -1.97 & -1.59 \\
\hline $\begin{array}{c}\text { Relative error between } 500 \mathrm{~m} \\
\text { MODIS and HJ-1A/B }(\%)\end{array}$ & -5.77 & -7.64 & -3.18 & -1.97 & -1.96 \\
\hline
\end{tabular}
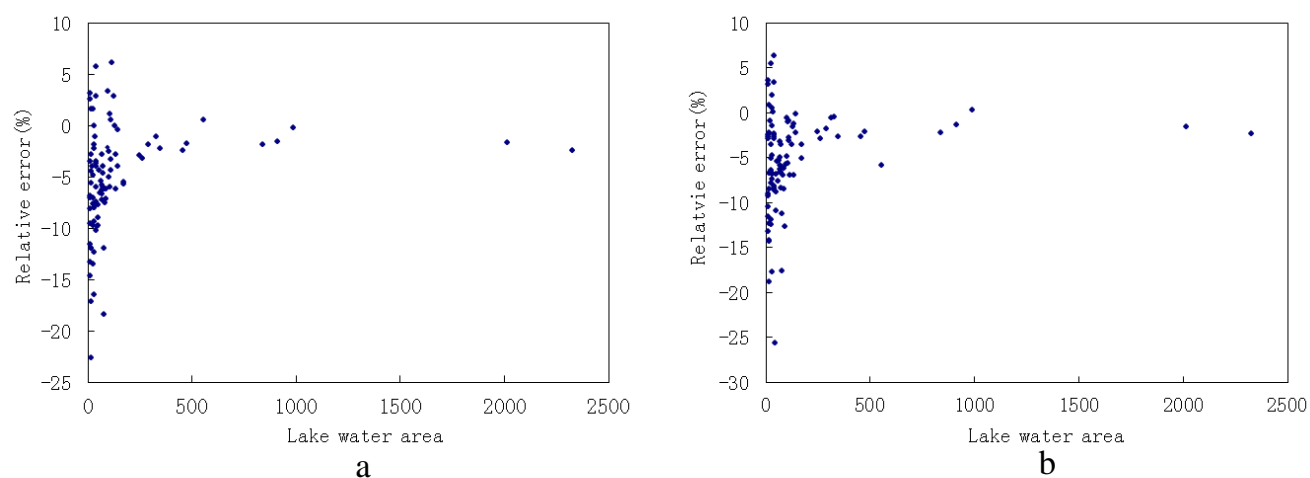

Figure 3. Relationship between Lake Water Area Estimated from HJ-1A/B and the Relative Error between the Lake Water Area Estimated from $\mathrm{HJ}$ 1A/B and MODIS. The Relative Error is Calculated with the Estimates Derived from $250 \mathrm{~m}$ MODIS and HJ-1A/B in a, and Calculated with the Estimates Derived from $500 \mathrm{~m}$ MODIS and HJ-1A/B in b

After analyzing the relationship between water area and SI1 estimated from $\mathrm{HJ}-1 \mathrm{~A} / \mathrm{B}$ data, it is found that SI1 decreased with lake water area increased. In order to compare the difference between the water area estimated from different spatial resolution images for different size lakes, all lakes were divided into five groups according to the lake water area estimated from $\mathrm{HJ}-1 \mathrm{~A} / \mathrm{B}$ data, as shown in table 2 . As lake size increases, the relative error between area estimates derived from MODIS and HJ-1A/B decreases gradually, and when the lake size is greater than $200 \mathrm{~km}^{2}$, the error is below $-2 \%$. Figure 3 shows the relationship between lake water area and the relative error between the area estimated from MODIS and HJ-1A/B data. When the lake is small, the relative error is not stable with a maximum of $-22 \%$; when lake water area is larger than $100 \mathrm{~km}^{2}$, the distribution of difference is relatively concentrated and mostly ranged from $-5 \%$ to $5 \%$.

\section{Summary and Conclusion}

HJ-1A/B CCD and MODIS imagers were used to study the difference in lake water area derived from different spatial resolution imagery. An integrated water body mapping method that combined the NDWI and near-infrared band was used to derive the water area information from $\mathrm{HJ}-1 \mathrm{~A} / \mathrm{B}$ imagery, and another method that combined the red and near-infrared band was used to derive the water area information from MODIS imagery. The thresholds of these two methods were determined by repeated experiments based on the histogram of image. Two patch shape indices SI1 and SI2 were also used to find the influence of the shape of lake on the water area extracted from HJ-1A/B and MODIS.

For lakes with area larger than $10 \mathrm{~km}^{2}$, the area estimates derived from $250 \mathrm{~m}$ MODIS and $500 \mathrm{~m}$ MODIS have strong correlations with those derived from HJ-1A/B data. The total area estimated from $250 \mathrm{~m}$ and $500 \mathrm{~m}$ MODIS are accurate and the accuracies of the two estimates are closer. Generally, the difference between the estimated areas from the $250 \mathrm{~m}$ and $500 \mathrm{~m}$ images decreased with the lake area increased. The difference between the estimated areas from $\mathrm{HJ}-1 \mathrm{~A} / \mathrm{B}$ and MODIS showed the same trend. Considering water area derived from $\mathrm{HJ}-1 \mathrm{~A} / \mathrm{B}$ as reference, it is found that the error of area estimate derived from MODIS is bigger when lake is small and lake shape is complex, and the error is smaller when the lake is big and the lake shape is simple. 
The shape of lake also has an influence on the results. The difference between the estimated lake water area from MODIS and HJ-1A/B shows an increasing trend as SI1 increased. However, since the SI1 has a strong dependence on the area of the lake, it may not be able to reflect the complexity of the lake well. In the future, we plan to use other index for further analysis.

\section{Acknowledgments}

This research was supported by the Scientific and Technological Research Program of Chongqing Municipal Education Commission (Grant No. KJ1401028) and National Natural Science Foundation of China (Grant No. 11426049).

\section{References}

[1] B. Lennox, I. Spooner, T. Jull and W. P. Patterson, "Post-glacial climate change and its effect on a shallow dimictic lake in Nova Scotia, Canada", Journal of Paleolimnology, vol. 43, no. 1, (2010), pp. 15-27.

[2] J. Stevenson, F. Siringan, J. Finn, D. Madulid and H. Heijnis, "Paoay Lake, northern Luzon, the Philippines: A record of Holocene environmental change", Global Change Biology, vol. 16, no. 6, (2010), pp. 1672-1688.

[3] Z. G. Hu, Y. T. Wang, T. H. Chi, S. H. Liu and J. T. Bi, "Monitoring lake areas based on mixed pixel decomposition combined with double-edge extration", Remote Sensing Information, vol. 22, no. 3, (2007), pp. 34-38.

[4] H. B. Wang, and M. G. Ma, "A review of monitoring change in lake water areas based on remote sensing", Remote Sensinge Technology and Application, vol. 24, no. 5, (2009), pp. 674-684.

[5] M. Ma, X. Wang, F. Veroustraete and L. Dong, "Change in area of Ebinur Lake during the 1998-2005 period", International Journal of Remote Sensing, vol. 28, no. 24, (2007), pp. 5523-5533.

[6] H. X. Ji, X. W. Fan, G. P. Wu and Y. B. Liu, "Accuracy comparison and analysis of methods for water area extraction of discrete lakes", Journal of Lake Sciences, vol. 27, no. 2, (2015), pp. 327-334.

[7] T. Cheng, R. M. Liu and X. Zhou, "Water information extraction method in Geographic National Conditions Investigation based on high resolution remote sensing images", Bulletin of Surveying and Mapping, no. 4, (2014), pp. 86-89.

[8] W. Q. Chen, J. L. Ding, Y. H. Li and Z. Y. Niu, "Extraction of water information based on China-made GF-1 remote sense image", Resources Science, vol. 37, no. 6, (2015), pp. 1166-1172.

[9] Y. Zhou, G. L. Xie, S. X. Wang, F. Wang and F. T. Wang, "Information Extraction of Thin Rivers around Built-up lands with false NDWI", Journal of Geo-information Science, vol. 16, no. 1, (2014), pp. 102107.

[10] S. L. Lu, B. F. Wu, N. N. Yan and H. Wang, "Water Body Mapping Method with HJ-1A/B Satellite Imagery", International Journal of Applied Earth Observation and Geoinformation, no. 13, (2011), pp. 428-434.

[11] Q. Y. Wang, R. X. Chen, J. Xu and X. L. Chen, "Research on Methods for Extracting Water Body Information from HJ-1A/B Data", Science Technology and Engineering, vol. 12. no. 13, (2012), pp. 3051-3056.

[12] L. Feng, C. M. Hu, X. L. Chen, X. B. Cai, L.Q. Tian and W. X. Gan, “Assessment of Inundation Changes of Poyang Lake Using MODIS Observations Between 2000 and 2010", Remote Sensing of Environment, no. 121, (2012), pp. 80-92.

[13] X. D. Li, J. S. Xiao, F. X. Li, R. X. Xiao, W. X. Xu and L. Wang, "Remote sensing monitoring of the Qinghai Lake based on EOS/MODIS data in recent 10 years", Journal of Natural Resources, vol. 27, no. 11, (2012), pp. 1962-1970.

[14] J. G. Xiong, S. X. Wang, Y. Zhou and F. L. Yan, "Influence of landscape pattern index on the area extracted from ETM+ and MODIS", Geomatics and Information Science of Wuhan University, vol. 36, no. 1, (2011), pp. 98-103.

[15] Y. Zhang, C. Z. Chen, G. P. Wu, X. W. Fan, X. Pan and Y. B. Liu, "Effects of spatial scale on water surface delineation with satellite images", Journal of Lake Sciences, vol. 27, no. 2, (2015), pp. 335-342.

[16] G. X. Bai, "China environmental and disaster monitoring and forecasting small satellite-HJ-1A/B", Aerospace China, no. 5, (2009), pp. 10-15.

[17] S. K. McFeeters, "Use of the Normalized Difference Water Index (NDWI) in the Delineation of Open Water Features", International Journal of Remote Sensing, vol. 17, no. 7, (1996), pp. 1425-1432.

[18] Y. Yang and R. Z. Ruan, "Extraction of Plain Lake water body based on TM imagery", Remote Sensing Information, no. 3, (2010), pp. 60-64. 


\section{Authors}

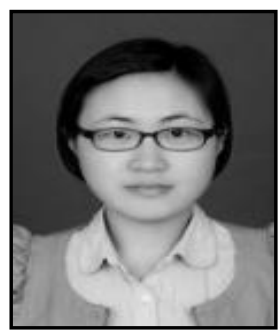

Rong XU She received her PhD in cartography and geographic information system (2013) from University of Chinese Academy of Sciences. Now she works at the School of Computer Science and Engineering, Chongqing Three Gorges University. She is making research on the information science and technology. 
International Journal of Signal Processing, Image Processing and Pattern Recognition Vol. 9, No. 4 (2016) 